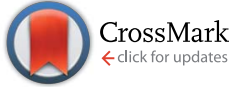

Cite this: RSC Adv., 2016, 6, 80408

Received 19th July 2016

Accepted 15th August 2016

DOI: $10.1039 / c 6 r a 18348 d$

www.rsc.org/advances

\section{Tuning the thermo- and mechanoresponsive behavior of luminescent cyclophanes $\uparrow$}

\begin{abstract}
Yoshimitsu Sagara, ${ }^{* a}$ Christoph Weder ${ }^{\mathrm{b}}$ and Nobuyuki Tamaoki ${ }^{\star a}$
Many cyclophanes have been investigated in dilute solution, where their internal cavities are accessible for supramolecular interactions. However, their photophysical properties in the solid state remain largely unexplored. We here report a new mechano- and thermoresponsive luminescent cyclophane that is comprised of two 9,10-bis(phenylethynyl)anthracene moieties and features two hexaethylene glycol bridges. The compound was found to exhibit a nematic liquid-crystalline phase at elevated temperature. $X$-ray diffraction patterns confirm that thermal and mechanical treatments induce changes in the molecular assembly, which are the basis for the observed photoluminescent color variations. The stimuli-responsive behavior of the new compound is quite different from that of a previously reported cyclophane with similar structure but shorter bridges. Thus, merely changing the ring size is an effective tool to tailor the stimuli-responsiveness and the phase behaviour of luminescent cyclophanes.
\end{abstract}

\section{Introduction}

Since the first report on [2.2] paracyclophane in $1949,{ }^{1}$ such bridged aromatic compounds have become widely investigated. ${ }^{2}$ Building on the synthetic pathways pioneered by Cram and Steinberg, ${ }^{3}$ a large number of cyclophanes have been synthesized over the years, originally on account of a general interest in molecules with unusual shape, high symmetry, and strained character. ${ }^{2,4}$ Eventually, it was recognized that their cavities render cyclophanes useful as supramolecular hosts, which have the ability to include guest molecules or ions. ${ }^{2,4 b, c, 5,6}$ This propensity was widely exploited by using cyclophanes as part of interlocked molecules such as catenanes and rotaxanes. ${ }^{6.77}$ In cases where the cyclophane comprises a fluorophore, the photoluminescence properties often change upon formation of inclusion complexes. ${ }^{6 e, 8-12}$ This behavior renders cyclophanes useful as fluorescent sensors, e.g., for the detection of biologically important ions and molecules..$^{6 e, 8-11}$ As a result, most studies on luminescent cyclophanes have focused on their investigation in solution, while their solid-state properties have remained little examined. ${ }^{13,14}$

Many compounds have been reported to display thermo- and mechanoresponsive luminescence characteristics, and which are possibly useful as sensing materials, in storage devices, and

${ }^{a}$ Research Institute for Electronic Science, Hokkaido University, N20, W10, Kita-Ku, Sapporo 001-0020, Japan. E-mail: sagara@es.hokudai.ac.jp; tamaoki@es.hokudai. ac.jp

${ }^{b}$ Adolphe Merkle Institute, University of Fribourg, Chemin des Verdiers 4, CH-1700 Fribourg, Switzerland

$\dagger$ Electronic supplementary information (ESI) available: Detailed synthetic schemes and additional absorption and fluorescence spectra. See DOI: 10.1039/c6ra18348d for security applications. ${ }^{15-20}$ In many cases, a stimuli-induced re-arrangement of the molecular assembly is the cause for the observed changes of the photoluminescence, because the photophysical properties often strongly depend on the molecular arrangement in the solid state. ${ }^{15}$ Thus, a reliable design strategy for thermo- and/or mechanoresponsive luminescent molecular materials is to create molecules that can assemble in several thermodynamically (meta)stable states. ${ }^{15 a}$ Many research groups have shown that this is generally possible by balancing the competition of different intermolecular interactions or using specific molecular structures that induce aggregationinduced emission properties..$^{15 a}$

With the objective to demonstrate that the integration of luminescent motifs into cyclic structures is another general approach to create stimuli-responsive luminescent compounds, we here report on the stimuli-responsive behaviour of the luminescent cyclophane 1 (Fig. 1). The new cyclophane is comprised of two 9,10-bis(phenylethynyl)anthracene moieties, which are connected by two hexaethylene glycol bridges. Unlike the linear reference compound 2, cyclophane $\mathbf{1}$ displays mechano- and thermoresponsive luminescence in the solid state. This finding follows our recent discovery of the thermoand mechanoresponsive behavior of cyclophane 3, which features the same luminophores as $\mathbf{1}$, but shorter bridges. ${ }^{14}$ Unfortunately, 3 displays a very low solubility in common organic solvents. We show here that the modification of the bridges between the 9,10-bis(phenylethynyl)anthracene moieties leads to an increase of the solubility, but more importantly, a completely different stimuli-responsive phase transition and photoluminescence color changing behavior were observed. Furthermore, compound $\mathbf{1}$ was found to exhibit a nematic liquid-crystalline (LC) phase. 

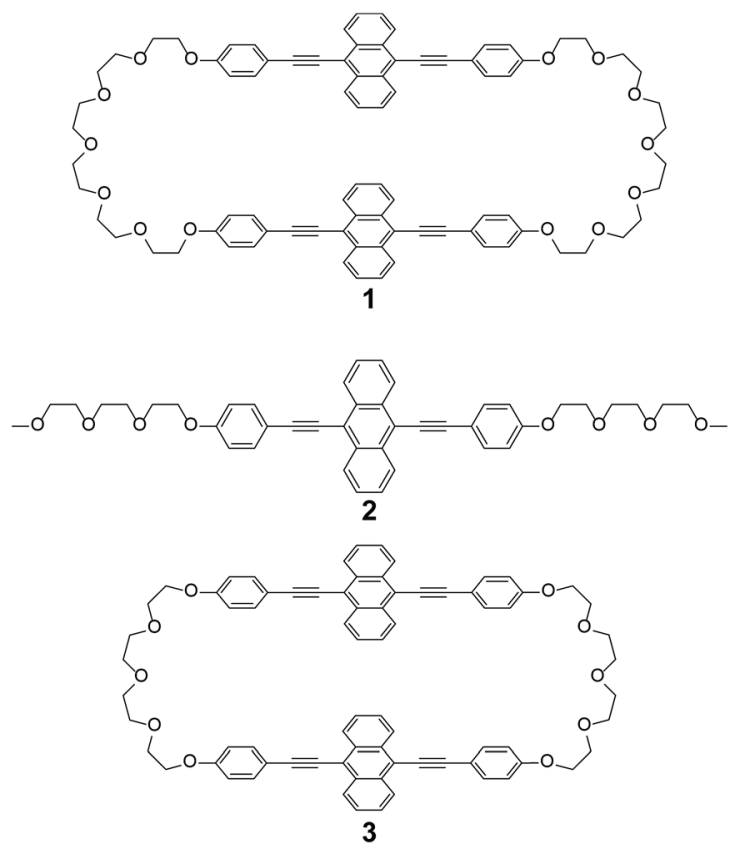

Fig. 1 Molecular structures of cyclophane 1, the linear reference compound 2, and previously reported cyclophane 3 .

\section{Results and discussion}

Hexaethylene glycol linkers were selected to bridge two 9,10bis(phenylethynyl)anthracene moieties to form compound $\mathbf{1}$. The flexible linkers were extended relative to those used in 3 and expected to enhance the solubility in common solvents and to decrease the phase transition temperatures. The linear compound 2 featuring the same luminophore was also synthesized for reference purposes. Compounds $\mathbf{1}$ and 2 were characterized by ${ }^{1} \mathrm{H}$ NMR, ${ }^{13} \mathrm{C}$ NMR, MALDI-TOF-MS spectra, and elemental analysis (see ESI $\dagger$ ). We found that compound 1 dissolves well in chloroform, dichloromethane, tetrahydrofuran, and $N, N$-dimethylformamide, whereas hot
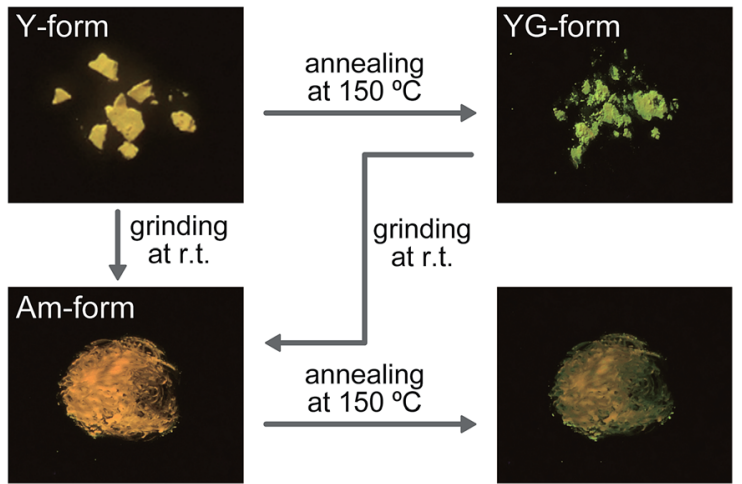

Fig. 2 Images presenting the photoluminescence color changes of cyclophane 1 in response to thermal and mechanical stimuli. Arrows indicate possible conversions by the indicated treatments. Images were taken on quartz substrates under irradiation with UV light $\left(\lambda_{\mathrm{ex}}=\right.$ $365 \mathrm{~nm}$ ) at room temperature. chloroform was needed to dissolve the previously reported cyclophane $\mathbf{3 .} .^{\mathbf{1 4}}$

Upon precipitating 1 from a concentrated chloroform solution into hexane, a yellow powder showing yellow photoluminescence was obtained (hereafter referred to as the Y-form). The Y-form can be converted to a yellowish-green emissive form (YG-form) through annealing at $150{ }^{\circ} \mathrm{C}$ for 10 min (Fig. 2). In the case of 3 , thermal treatment results in a conversion from a yellow emissive crystal to a reddish-orange emissive crystal. ${ }^{14}$ Thus, the direction of the thermally induced photoluminescence spectral shift of $\mathbf{1}$ is opposite to that of $\mathbf{3}$. Upon mechanically grinding the Y- or YG-form of $\mathbf{1}$, a yellow emissive amorphous form (Am-form) was obtained. When the Am-form was annealed at $150{ }^{\circ} \mathrm{C}$ for $10 \mathrm{~min}$, a mixture was obtained that showed both yellow and green emission. Though the Y-form never recovers after thermal or mechanical treatment in the solid state, reprecipitation regenerates the Y-form. In sharp contrast to cyclophane $\mathbf{1}$, the reference compound $\mathbf{2}$ does not display similar changes of its photoluminescence color in response to thermal or mechanical stimuli in the solid state. Motivated by these differences, we investigated the relationship between the photophysical properties and the molecular assembled structures of cyclophane $\mathbf{1}$ in more detail.

The photophysical properties of cyclophane $\mathbf{1}$ and the linear reference compound 2 were first probed in dilute chloroform solutions $\left(c=1 \times 10^{-5} \mathrm{M}\right)$. The absorption and emission spectra of 2 show the typical spectral features of the 9,10bis(phenylethynyl)anthracene motif (Fig. 3, grey line). The absorption band displays two peaks at 450 and $471 \mathrm{~nm}$ with similar molar absorption coefficient $\left(\varepsilon=4.1 \times 10^{4} \mathrm{~L} \mathrm{~mol}^{-1}\right.$ $\mathrm{cm}^{-1}, 4.0 \times 10^{4} \mathrm{~L} \mathrm{~mol}^{-1} \mathrm{~cm}^{-1}$, respectively) (Fig. 3a). A vibronic structure was observed in the emission band with two peaks at 493 and $522 \mathrm{~nm}$ and a shoulder around at $560 \mathrm{~nm}$ (Fig. 3b). Fig. 4a shows the result of an emission lifetime measurement conducted for a dilute chloroform solution of $2\left(\mathrm{ca} .1 \times 10^{-6} \mathrm{M}\right)$. The decay profile is well fitted by a single exponential decay function with a lifetime of $3.1 \mathrm{~ns}$. These results match literature data of a similar linear compound well ${ }^{21}$ and indicate that compound 2 is indeed well-individualized in the chloroform solutions measured.
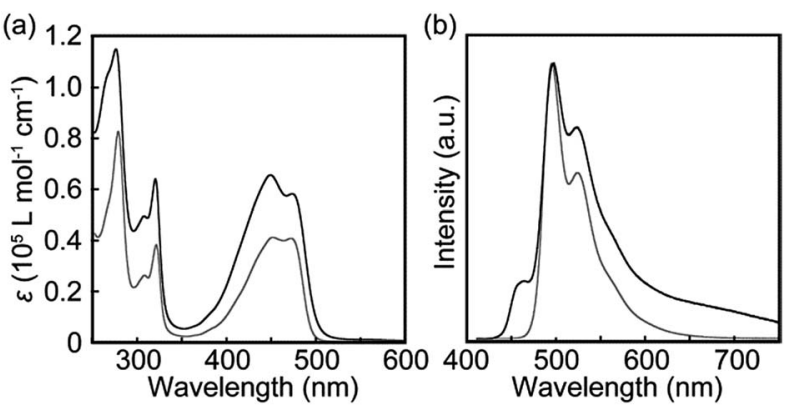

Fig. 3 (a) Absorption and (b) photoluminescence spectra of chloroform solutions of cyclophane $1\left(c=1 \times 10^{-5} \mathrm{M}\right.$; black line) and the linear reference compound 2 ( $c=1 \times 10^{-5} \mathrm{M}$; grey line). All spectra were recorded at room temperature. Photoluminescence spectra were recorded with excitation at $400 \mathrm{~nm}$ and were normalized to the intensity of the monomer peak. 
The chloroform solution of $\mathbf{1}$ displays an absorption spectrum which is slightly different from that of compound 2 (Fig. 3a). Two peaks are observed at 449 and $474 \mathrm{~nm}$ with extinction coefficients, $\varepsilon$, of $6.5 \times 10^{4} \mathrm{~L} \mathrm{~mol}^{-1} \mathrm{~cm}^{-1}$ and $5.8 \times$ $10^{4} \mathrm{~L} \mathrm{~mol}^{-1} \mathrm{~cm}^{-1}$. The fact that they are different and not twice as large as those of compound 2 is indicative of electronic ground-state interactions between the two chromophores in cyclophane 1. Similar changes of the absorption spectral shapes have been observed for other cyclophanes that contain two perylene moieties and in which the chromophores form an $\mathrm{H}^{-}$ type geometry. ${ }^{22}$

The emission spectrum of the chloroform solution of $\mathbf{1}$ is also unambiguously different from that of 2 , as shown in Fig. 3b. Besides the monomer emission peak at $493 \mathrm{~nm}$, a new band with maximum at $464 \mathrm{~nm}$ is observed, which is ascribed to exciton coupling with H-type geometry of the two emission cores; this interpretation is supported by the fact that the molar extinction coefficient at $471 \mathrm{~nm}$ is larger than that at $450 \mathrm{~nm}$ (Fig. 3a). Moreover, such an emission peak at shorter wavelength region was also observed for compound $3 .{ }^{14}$ In ideal $\mathrm{H}^{-}$ aggregates, radiative relaxation from the higher energy level resulting from splitting of the lowest unoccupied molecular orbital of monomer is forbidden. ${ }^{23}$ However, twisted arrangements of the luminophores allow direct radiative transition from the forbidden state. Because the absorption spectral feature does not change and the emission peak at $464 \mathrm{~nm}$ remains unchanged in the concentration range from $1 \times 10^{-5}$ $\mathrm{M}$ to $1 \times 10^{-6} \mathrm{M}$ (Fig. $\left.\mathrm{S} 1 \dagger\right)$, the exciton coupling must arise from an intramolecular H-type geometry and not intermolecular interactions.

Another characteristic of the emission spectrum of the chloroform solution of $\mathbf{1}$ is the non-negligible emission intensity between 600 and $750 \mathrm{~nm}$ (Fig. 3b), which is ascribed to the formation of excimers. ${ }^{24}$ Indeed, a longer emission lifetime of $8.6 \mathrm{~ns}$ was observed when the emission decay profile was monitored at $650 \mathrm{~nm}$ (Fig. 4b, grey line), whereas much shorter lifetimes $(0.2,0.6$, and $2.2 \mathrm{~ns})$ were obtained when the decay was monitored at $500 \mathrm{~nm}$ (Fig. 4b, black line). The broad emission band was also observed for a chloroform solution at lower concentration (Fig. S1, $\dagger c=1 \times 10^{-6} \mathrm{M}$ ), suggesting that the
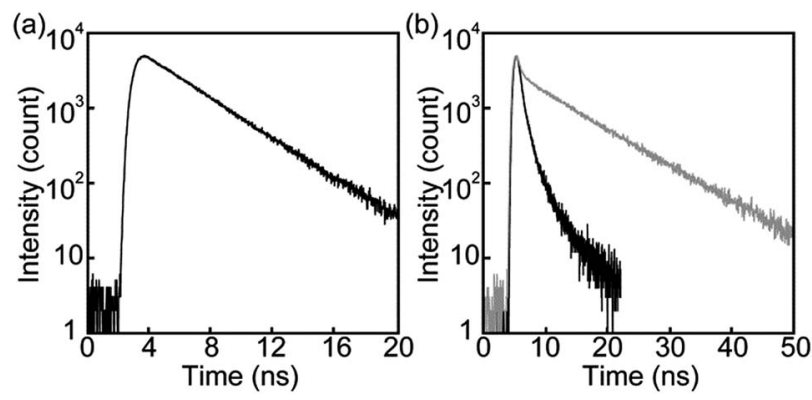

Fig. 4 Emission decay profiles of chloroform solutions of (a) the linear reference compound 2 collected at $500 \mathrm{~nm}$ and (b) cyclophane 1 collected at $500 \mathrm{~nm}$ (black line) and $650 \mathrm{~nm}$ (grey line). All profiles were measured at room temperature with $\lambda_{\mathrm{ex}}=405 \mathrm{~nm}$ and at concentrations of ca. $1 \times 10^{-6} \mathrm{M}$.

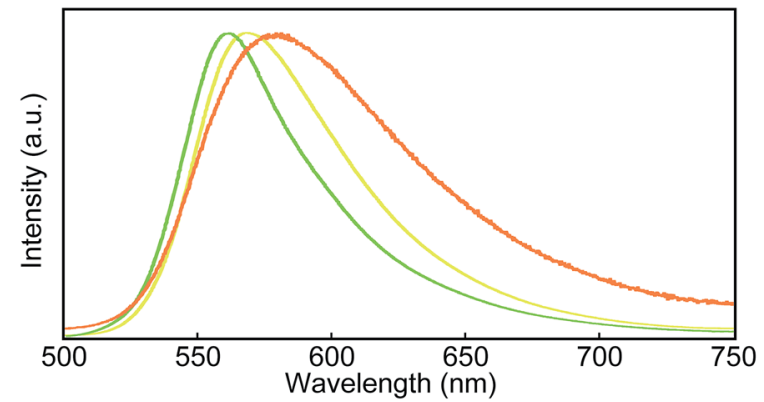

Fig. 5 Photoluminescence spectra of the $Y$-form (yellow line), the YGform (green line), and the ground YG-form (orange line) of cyclophane 1. All spectra were recorded at room temperature with $\lambda_{\mathrm{ex}}=400 \mathrm{~nm}$.

long-wavelength tail is predominantly related to intramolecular excimers. The intramolecular exciton coupling and excimer formation significantly decreases the emission quantum yield $\Phi$. Whereas the quantum yield of the linear reference compound 2 in chloroform solution is 0.90 , it is reduced to 0.14 in the case of 1 . Interestingly, $\Phi$ is still twice as large as that of cyclophane $3(\Phi=0.07)$ under similar conditions. ${ }^{\mathbf{1 4}}$

Steady-state photoluminescence spectra of $\mathbf{1}$ in the solid states were also measured at room temperature (Fig. 5). The emission band of the Y-form is structureless and displays only one maximum at $567 \mathrm{~nm}$. Annealing the Y-form at $150{ }^{\circ} \mathrm{C}$ for 10 min results in a blue shift of the emission band $\left(\lambda_{\mathrm{em}, \max }=560\right.$ $\mathrm{nm}$ ) and the band narrows a bit. The thermally induced change of the emission characteristics matches the photoluminescence color change from yellow to yellowish-green after the transition from the Y-form to the YG-form (Fig. 2). Emission decay profiles of the Y- and YG-form were measured to confirm that the emissive species contributing to each emission band are different from each other. Indeed, as shown in Fig. 6, the decay profiles are clearly different, but both could be fitted with triexponential decay functions. Whereas a long lifetime of $20 \mathrm{~ns}$ indicative of excimers was detected for the Y-form, no emissive species with such a long lifetime was observed for the YG-form (Table 1). When the YG-form was ground, the emission band was redshifted and broadened, which reflects the amorphous nature of the Am-form (vide infra). In the amorphous state,

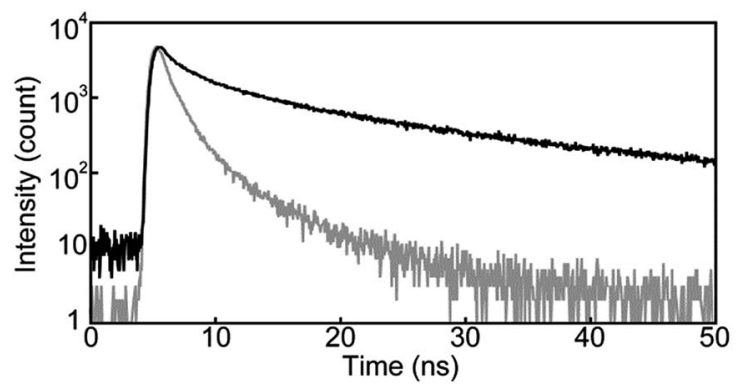

Fig. 6 Emission decay profiles of the $Y$-form of cyclophane 1 collected at $600 \mathrm{~nm}$ (black line) and the YG-form of cyclophane 1 collected at $560 \mathrm{~nm}$ (grey line). All profiles were measured at room temperature with $\lambda_{\mathrm{ex}}=405 \mathrm{~nm}$. 
Table 1 Emission lifetime and quantum yield of compounds 1 and $2^{a}$

\begin{tabular}{|c|c|c|c|}
\hline & $\tau_{\mathrm{i}}(\mathrm{ns})$ & $X^{2}$ & $\Phi_{\mathrm{PL}}$ \\
\hline 1 in chloroform ${ }^{b}$ & $0.2,0.6,2.2$ & 1.09 & 0.14 \\
\hline 1 in chloroform ${ }^{c}$ & $0.5,8.6$ & 1.06 & \\
\hline Y-Form $^{d}$ & $0.9,4.8,20$ & 1.09 & 0.20 \\
\hline YG-Form $^{e}$ & $0.4,1.1,3.9$ & 1.01 & 0.14 \\
\hline 2 in chloroform ${ }^{b}$ & 3.1 & 1.03 & 0.90 \\
\hline
\end{tabular}

various arrangements of the emissive cores of $\mathbf{1}$ exist, and energy transfer can be expected to occur from higher energy sites to excimers. Annealing of the Am-form of 1 at $150{ }^{\circ} \mathrm{C}$ for 10 min affords an inhomogeneous solid that shows both green and yellow emission depending on the parts, which means cyclophane 1 forms several molecular arrangements. While compound 1 exhibits unambiguous emission color changes, the linear reference compound 2 never shows clear color changes in response to mechanical stimuli, though vibronic structure could be seen in the emission spectrum after grinding as shown in Fig. 7.

To gain further insights into the color changing behavior, we investigated the phase behavior of the cyclophane $\mathbf{1}$ and the linear compound 2. Fig. 8 shows differential scanning calorimetry (DSC) curves (first heating) of the Y-form and the YGform of 1 and the reference compound 2. Upon heating the Yform, a weak exothermic peak appears at $116.3{ }^{\circ} \mathrm{C}$, which is ascribed to a phase transition from the Y-form to the YG-form. The DSC curve also displays two endothermic peaks at $\mathbf{1 5 9 . 6}$ and $168.6{ }^{\circ} \mathrm{C}$. The former peak is corresponding to a phase transition from the YG-form to another yellow emissive crystalline phase, whereas the latter peak is due to a phase transition to a LC phase (vide infra). Heating to above $250{ }^{\circ} \mathrm{C}$ leads to decomposition of $\mathbf{1}$ and no discrete clearing temperature could be discerned. Because the thermogravimetric analysis (TGA) trace of 1 (Fig. 9) shows no clear weight loss below $250{ }^{\circ} \mathrm{C}$, the phase transition at $116.3{ }^{\circ} \mathrm{C}$ is not caused by the release of trapped solvent. The powder XRD patterns of cyclophane 1 confirm that the observed color change from yellow to

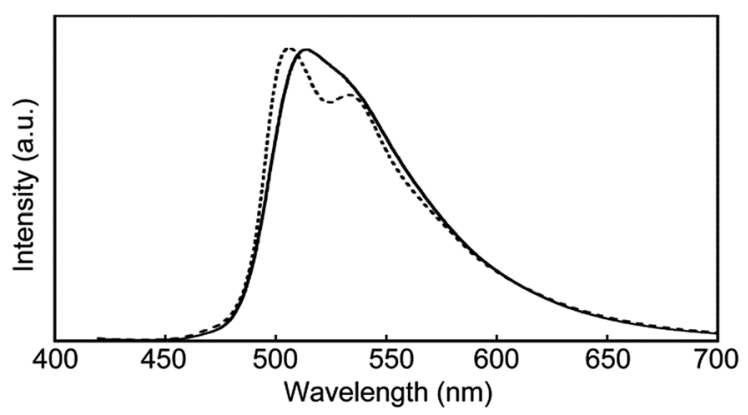

Fig. 7 Photoluminescence spectra of the linear reference compound 2 in the solid state before (solid line) and after (dotted line) grinding. All spectra were recorded at room temperature with $\lambda_{\text {ex }}=400 \mathrm{~nm}$.

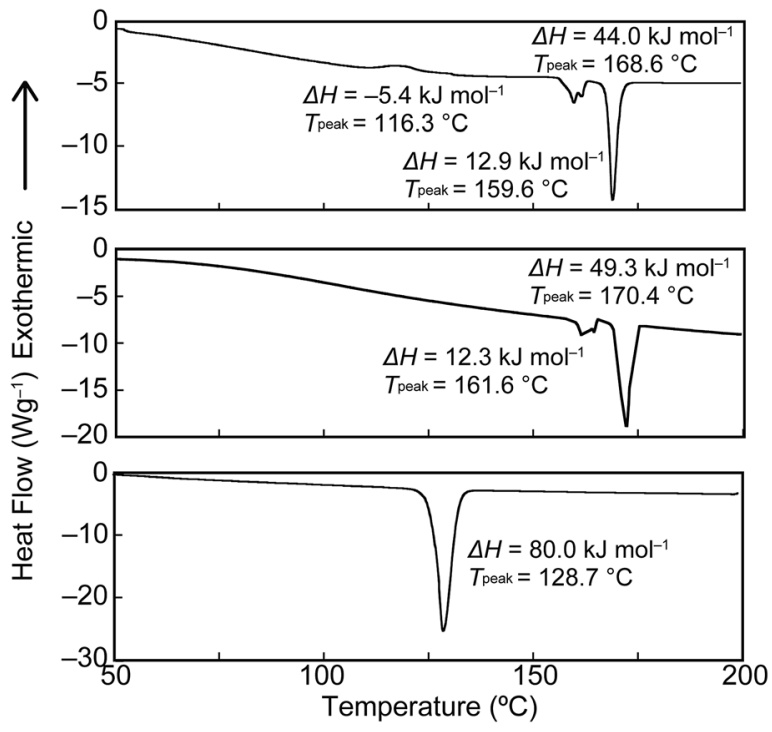

Fig. 8 First heating DSC traces of the Y-form (top) and the YG-form (middle) of cyclophane 1, and the linear reference compound 2 (bottom)

yellowish-green (Y-form $\rightarrow$ YG-form) is ascribed to the change of the molecular assembled state. As shown in Fig. 10, the XRD patterns of both the Y- and YG-form show many peaks, indicative of their crystalline nature. However, the peak positions of the Y-form are clearly different from those of the YG-form, pointing to different crystal structures. As the peak observed in the DSC of the Y-form of $\mathbf{1}$ at $116.3{ }^{\circ} \mathrm{C}$ upon heating is exothermic, the transition from the Y-form to YG-form is a transition from thermodynamically metastable to stable state. Indeed, the YG-form shows no peaks in the DSC curve upon heating (Fig. 8, middle). In the previous study, cyclophane 3 having tetraethylene glycol as the bridge linkers gave one endothermic peak at $221{ }^{\circ} \mathrm{C}$ on heating until the compound shows decomposition, which coincides with the photoluminescence color change from yellow to reddish orange. ${ }^{\mathbf{1 4}}$ Just elongation of linkers gives clear changes in the phase transition and color changing behavior.

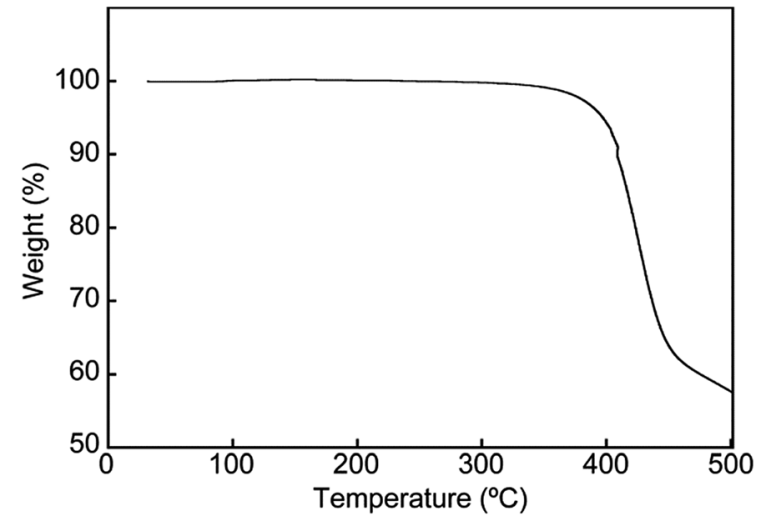

Fig. 9 TGA curve acquired for the $Y$-form of cyclophane 1. The measurement was conducted under $\mathrm{N}_{2}$. 


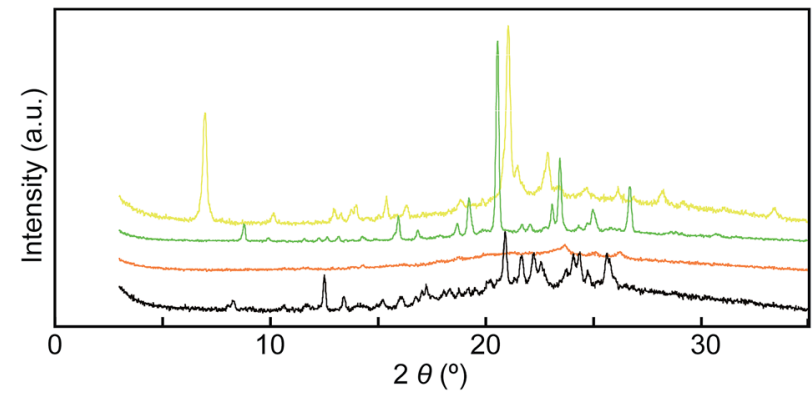

Fig. 10 Powder $X$-ray diffraction patterns of cyclophane 1 in the $Y$ form (yellow line), the YG-form (green line), the Am-form (orange line), and the annealed Am-form (black line). All measurements were carried out at room temperature.

Mechanical grinding significantly affects the XRD patterns of cyclophane 1. As shown in Fig. 10, all sharp peaks disappear in the XRD pattern for the Am-form that had been prepared by grinding the Y-form (Fig. 10, orange line), indicating that cyclophane 1 forms an amorphous solid after grinding. Subsequent annealing leads to the appearance of many peaks (Fig. 10, black line), but the diffraction pattern is different from those of the Y- and YG-forms. This result suggests that cyclophane $\mathbf{1}$ forms several other molecular assembled structures, because both yellow and green emissive parts were concomitantly obtained after thermal treatment (Fig. 2). Because one exothermic peak was observed on the DSC curve of the Am-form (Fig. S2 $\dagger$ ), the Am-form was thermodynamically metastable. In the case of cyclophane 3, annealing the ground sample recovers the original XRD pattern. ${ }^{14}$ Therefore, elongation of spacer chains allows compound $\mathbf{1}$ to display a more complicated phase transition behavior.

Moreover, compound 1 shows a LC phase above $168.6{ }^{\circ} \mathrm{C}$, very much in contrast to the previously reported cyclophane 3 (ref. 14) and the linear reference compound 2. The XRD pattern measured at $190{ }^{\circ} \mathrm{C}$ (Fig. 11) shows no clear peaks, pointing to a nematic phase. This is supported by the very low viscosity and the schlieren texture observed in polarized optical microscopic images (Fig. 12). An LC texture was also reported for other cyclic compounds. ${ }^{25}$ It is noteworthy that the reference compound 2 displays no thermotropic behavior; indeed, the DSC trace shows only one endothermic peak corresponding to a transition from crystal to isotropic phase at $128.7^{\circ} \mathrm{C}$ (Fig. 8, bottom). Thus, it appears that the cyclic structure of 1 restricts the stable and closed packing of molecules, resulting in the appearance of an LC phase.

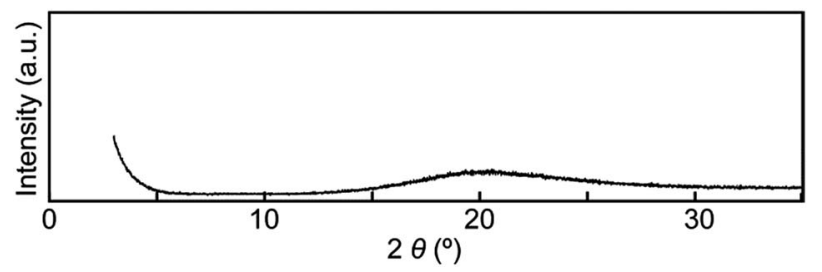

Fig. 11 Powder X-ray diffraction pattern of cyclophane 1 at $190^{\circ} \mathrm{C}$.

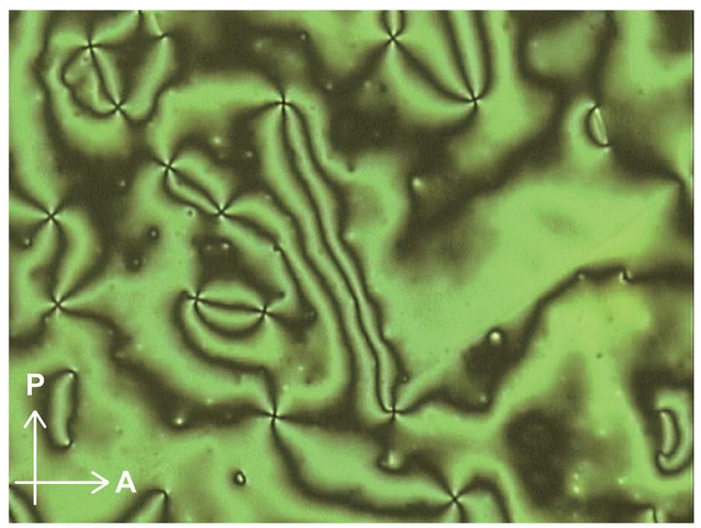

Fig. 12 Polarized optical microscopic image of cyclophane 1 at $200^{\circ} \mathrm{C}$

\section{Conclusions}

In conclusion, our results suggest that the thermo- and mechanoresponsive luminescence behavior of cyclophanes is a general effect that should be broadly exploitable. Cyclophane 1 exhibits clear color changes upon mechanical grinding and exposure to heat, whereas the linear reference compound 2 shows no such changes. The stimuli-responsive behavior of the new compound is quite different than that of a previously reported cyclophane with similar structure but shorter bridges, which demonstrates that merely changing the ring size is allows one to change the stimuli-responsiveness and the phase behavior of luminescent cyclophanes in a significant manner. Our finding clearly confirms that the integration of luminescent motifs into cyclic structures is a promising approach to create luminescent compounds with stimuli-responsive properties in the solid states.

\section{Experimental section}

All reagents and solvents were purchased from Aldrich and Tokyo Kasei. Unless otherwise noted, all reactions were carried out under nitrogen atmosphere. Silica gel column chromatography was carried out with silica gel from Kanto Chemicals (silica gel $60 \mathrm{~N}$, spherical, 63-210 $\mu \mathrm{m}$ ). ${ }^{1} \mathrm{H}$ NMR spectra were recorded on a JEOL JNM-ECX 400 spectrometer and all chemical shifts are quoted on the $\delta$-scale in ppm relative to the signal of tetramethylsilane (at 0.00) as an internal standard. Protondecoupled ${ }^{13} \mathrm{C}$ NMR spectra were recorded on a JEOL JNMECX 400 spectrometer and all chemical shifts $(\delta)$ are reported in ppm using residual solvent as the internal standard $\left(\mathrm{CDCl}_{3}\right.$ at 77.16). Coupling constants $(J)$ are reported in $\mathrm{Hz}$ and relative intensities are also shown. Elemental analysis was conducted with an Exeter Analytical CE440 Elemental Analyzer. Matrixassisted laser desorption ionization time-of-flight (MALDITOF) mass spectra were measured on an AB SCIEX TOF/TOF 5800. The DSC measurements were carried out using a Rigaku Thermo plus EVO DSC8230 with heating/cooling rates of $10{ }^{\circ} \mathrm{C}$ $\min ^{-1}$ under nitrogen atmosphere. The thermogravimetric 
analysis was conducted using a Rigaku Thermo plus TG8120 under nitrogen atmosphere. Powder X-ray diffraction experiments were conducted with a Rigaku SmartLab. An Anton Paar DHS1100 was attached to the Rigaku SmartLab for PXRD measurements at elevated temperature. UV-vis absorption spectra were recorded on a JASCO V-550. Steady-state fluorescence spectra were recorded on a JASCO FP-6500. The solid samples for steady-state fluorescence spectra were carefully sandwiched between quartz substrates and were set in the sample chamber of the spectrometer so that the detector gathers fluorescence from the surface of the sandwiched solid. Time-resolved fluorescence measurements were carried out with a Hamamatsu Photonics Quantaurus-Tau at room temperature. Quantum efficiencies were measured with a Hamamatsu Photonics Quantaurus-QY at room temperature. Optical microscopy was conducted with an Olympus BX-60 optical microscope equipped with a Sony DXC-950 3CCD camera and a Mettler Toledo FP 90 hot stage. Cyclophane 1 was simply placed on a glass substrate for this experiment, because the compound was observed to show a strong tendency for homeotropic alignment when sandwiched between glass substrates, leading to disappearance of the schlieren texture.

\section{Acknowledgements}

We thank Prof. Y. Urano for emission lifetime measurements and quantum yield measurements and Y. Takahashi and Prof. S. Noro for DSC measurements and TGA. Y. S. acknowledges support from JSPS KAKENHI Grant Numbers JP16K17885 and JP16H00818. Y. S. also acknowledges support from the Asahi Glass Foundation. C. W. acknowledges support from the National Center of Competence in Research (NCCR) BioInspired Materials, a research instrument of the Swiss National Science Foundation, the European Research Council (ERC-2011-AdG 291490-MERESPO), and the Adolphe Merkle Foundation.

\section{Notes and references}

1 (a) C. J. Brown and A. C. Farthing, Nature, 1949, 164, 915916; (b) H. Hopf, Isr. J. Chem., 2012, 52, 18-19.

2 Modern Cyclophane Chemistry, ed. R. Gleiter and H. Hopf, Wiley-VCH, Weinheim, 2004.

3 D. J. Cram and H. Steinberg, J. Am. Chem. Soc., 1951, 73, 5691-5704.

4 (a) D. J. Cram and J. M. Cram, Acc. Chem. Res., 1971, 4, 204213; (b) C. Seel and F. Vögtle, Angew. Chem., Int. Ed. Engl., 1992, 31, 528-549; (c) J. O. Jeppesen, M. B. Nielsen and J. Becher, Chem. Rev., 2004, 104, 5115-5131; (d) P. G. Ghasemabadi, T. Yao and G. J. Bodwell, Chem. Soc. Rev., 2015, 44, 6494-6518.

5 J.-M. Lehn, Science, 1993, 260, 1762-1763.

6 (a) R. M. Izatt, K. Pawlak, J. S. Bradshaw and R. L. Bruening, Chem. Rev., 1995, 95, 2529-2586; (b) F. P. Schmidtchen and M. Berger, Chem. Rev., 1997, 97, 1609-1646; (c) A. Jasat and J. C. Sherman, Chem. Rev., 1999, 99, 931-967; (d) E. A. Meyer, R. K. Castellano and F. Diederich, Angew.
Chem., Int. Ed., 2003, 42, 1210-1250; (e) D. Ramaiah, P. P. Neelakandan, A. K. Nair and R. R. Avirah, Chem. Soc. Rev., 2010, 39, 4158-4168; (f) M. Xue, Y. Yang, X. Chi, Z. Zhang and F. Huang, Acc. Chem. Res., 2012, 45, 1294-1308. 7 (a) D. B. Amabilino and J. F. Stoddart, Chem. Rev., 1995, 95, 2725-2828; (b) V. Balzani, M. Gomez-Lopez and J. F. Stoddart, Acc. Chem. Res., 1998, 31, 405-414; (c) A. R. Pease, J. O. Jeppesen, J. F. Stoddart, Y. Luo, C. P. Collier and J. R. Heath, Acc. Chem. Res., 2001, 34, 433-444; (d) A. H. Flood, Y. Liu and J. F. Stoddart, in Modern Cyclophane Chemistry, ed. R. Gleiter and H. Hopf, Wiley-VCH, Weinheim, 2005, pp. 485-518; (e) I. Aprahamian, O. S. Miljanic, W. R. Dichtel, K. Isoda, T. Yasuda, T. Kato and J. F. Stoddart, Bull. Chem. Soc. Jpn., 2007, 80, 1856-1869; $(f)$ A. C. Fahrenbach, C. J. Bruns, D. Cao and J. F. Stoddart, Acc. Chem. Res., 2012, 45, 15811592.

8 (a) P. Čudić, M. Žinić, V. Tomišić, V. Simeon, J.-P. Vigneron and J.-M. Lehn, J. Chem. Soc., Chem. Commun., 1995, 10731075; (b) M.-P. Teulade-Fichou, J.-P. Vigneron and J.-M. Lehn, J. Chem. Soc., Perkin Trans. 2, 1996, 2, 21692175; (c) O. Baudoin, F. Gonnet, M.-P. Teulade-Fichou, J.-P. Vigneron, J.-C. Tabet and J.-M. Lehn, Chem.-Eur. J., 1999, 5, 2762-2771.

9 (a) P. P. Neelakandan and D. Ramaiah, Angew. Chem., Int. Ed., 2008, 47, 8407-8411; (b) P. P. Neelakandan, K. S. Sanju and D. Ramaiah, Photochem. Photobiol., 2010, 86, 282-289.

10 (a) M. Inouye, K. Fujimoto, M. Furusyo and H. Nakazumi, J. Am. Chem. Soc., 1999, 121, 1452-1458; (b) H. Abe, Y. Mawatari, H. Teraoka, K. Fujimoto and M. Inouye, J. Org. Chem., 2004, 69, 495-504.

11 L. Qiu, C. Zhu, H. Chen, M. Hu, W. He and Z. Guo, Chem. Commun., 2014, 50, 4631-4634.

12 P. Spenst and F. Würthner, Angew. Chem., Int. Ed., 2015, 54, 10165-10168.

13 P. C. Nandajan, P. P. Neelakandan and D. Ramaiah, $R S C$ Adv., 2013, 3, 5624-5630.

14 Y. Sagara, Y. C. Simon, N. Tamaoki and C. Weder, Chem. Commun., 2016, 52, 5694-5697.

15 (a) Y. Sagara, S. Yamane, M. Mitani, C. Weder and T. Kato, Adv. Mater., 2016, 28, 1073-1095; (b) K. Araki and T. Mutai, Photochemistry, 2016, 43, 191-225; (c) T. Seki and H. Ito, Chem.-Eur. J., 2016, 22, 4322-4329; (d) J. Mei, N. L. C. Leung, R. T. K. Kwok, J. W. Y. Lam and B. Z. Tang, Chem. Rev., 2015, 115, 11718-11940; (e) A. P. Haehnel, Y. Sagara, Y. C. Simon and C. Weder, Top. Curr. Chem., 2015, 369, 345-375; (f) Z. Ma, Z. Wang, M. Teng, Z. Xu and X. Jia, ChemPhysChem, 2015, 16, 1811-1828; $(g)$ F. Ciardelli, G. Ruggeri and A. Pucci, Chem. Soc. Rev., 2013, 42, 857870; (h) X. Zhang, Z. Chi, Y. Zhang, S. Liu and J. Xu, J. Mater. Chem. C, 2013, 1, 3376-3390; (i) Z. Chi, X. Zhang, B. Xu, X. Zhou, C. Ma, Y. Zhang, S. Liu and J. Xu, Chem. Soc. Rev., 2012, 41, 3878-3896; (j) Y. Sagara and T. Kato, Nat. Chem., 2009, 1, 605-610.

16 (a) A. Seeboth, D. Lötzsch, R. Ruhmann and O. Muehling, Chem. Rev., 2014, 114, 3037-3068; (b) J. Lott, C. Ryan, B. Valle, J. R. Johnson, D. A. Schiraldi, J. Shan, K. D. Singer 
and C. Weder, Adv. Mater., 2011, 23, 2425-2429; (c) S. Yamane, Y. Sagara and T. Kato, Chem. Commun., 2009, 3597-3599; (d) Y. Zhao, H. Gao, Y. Fan, T. Zhou, Z. Su, Y. Liu and Y. Wang, Adv. Mater., 2009, 21, 3165-3169; (e) N. S. S. Kumar, S. Varghese, N. P. Rath and S. Das, J. Phys. Chem. C, 2008, 112, 8429-8437; (f) T. Mutai, H. Tomoda, T. Ohkawa, Y. Yabe and K. Araki, Angew. Chem., Int. Ed., 2008, 47, 9522-9524; $(g)$ T. Mutai, H. Satou and K. Araki, Nat. Mater., 2005, 4, 685-687; (h) A. Kishimura, T. Yamashita, K. Yamaguchi and T. Aida, Nat. Mater., 2005, 4, 546-549; (i) R. Davis, N. P. Rath and S. Das, Chem. Commun., 2004, 74-75.

17 (a) T. Seki, Y. Takamatsu and H. Ito, J. Am. Chem. Soc., 2016, 138, 6252-6260; (b) Y. Sagara, A. Lavrenova, A. Crochet, Y. C. Simon, K. M. Fromm and C. Weder, Chem.-Eur. J., 2016, 22, 4374-4378; (c) Z. Ma, Z. Wang, X. Meng, Z. Ma, Z. Xu, Y. Ma and X. Jia, Angew. Chem., Int. Ed., 2016, 55, 519-522; (d) T. Seki, T. Ozaki, T. Okura, K. Asakura, A. Sakon, H. Uekusa and H. Ito, Chem. Sci., 2015, 6, 21872195; (e) H.-J. Kim, D. R. Whang, J. Gierschner, C. H. Lee and S. Y. Park, Angew. Chem., Int. Ed., 2015, 54, 4330-4333; (f) S. Yagai, S. Okamura, Y. Nakano, M. Yamauchi, K. Kishikawa, T. Karatsu, A. Kitamura, A. Ueno, D. Kuzuhara, H. Yamada, T. Seki and H. Ito, Nat. Commun., 2014, 5, 4013; $(g)$ R. Li, S. Xiao, Y. Li, Q. Lin, R. Zhang, J. Zhao, C. Yang, K. Zou, D. Li and T. Yi, Chem. Sci., 2014, 5, 3922-3928; (h) K. Nagura, S. Saito, H. Yusa, H. Yamawaki, H. Fujihisa, H. Sato, Y. Shimoikeda and S. Yamaguchi, J. Am. Chem. Soc., 2013, 135, 10322-10325; (i) T. Seki, K. Sakurada and H. Ito, Angew. Chem., Int. Ed., 2013, 52, 12828-12832; (j) H. Ito, M. Muromoto, S. Kurenuma, S. Ishizaka, N. Kitamura, H. Sato and T. Seki, Nat. Commun., 2013, 4, 2009; (k) W. Z. Yuan, Y. Q. Tan, Y. Y. Gong, P. Lu, J. W. Y. Lam, X. Y. Shen, C. F. Feng, H. H.-Y. Sung, Y. W. Lu, I. D. Williams, J. Z. Sun, Y. M. Zhang and B. Z. Tang, Adv. Mater., 2013, 25, 2837-2843; (l) Y. Dong, B. Xu, J. Zhang, X. Tan, L. Wang, J. Chen, H. Lv, S. Wen, B. Li, L. Ye, B. Zou and W. Tian, Angew. Chem., Int. Ed., 2012, 51, 10782-10785; (m) Y. Ren, W. H. Kan, V. Thangadurai and T. Baumgartner, Angew. Chem., Int. Ed., 2012, 51, 3964-3968; (n) J. Wang, J. Mei, R. Hu, J. Z. Sun, A. Qin and B. Z. Tang, J. Am. Chem. Soc., 2012, 134, 9956-9966; (o) M. Sase, S. Yamaguchi, Y. Sagara, I. Yoshikawa, T. Mutai and K. Araki, J. Mater. Chem., 2011, 21, 8347-8354; (p) G. Zhang, J. Lu, M. Sabat and C. L. Fraser, J. Am. Chem. Soc., 2010, 132, 2160-2162; (q) S.-J. Yoon, J. W. Chung, J. Gierschner, K. S. Kim, M.-G. Choi, D. Kim and S. Y. Park, J. Am. Chem. Soc., 2010, 132, 13675-13683; (r) J. Kunzelman, M. Kinami, B. R. Crenshaw, J. D. Protasiewicz and C. Weder, Adv. Mater., 2008, 20, 119-122; (s) Y. Sagara, T. Mutai, I. Yoshikawa and K. Araki, J. Am. Chem. Soc., 2007, 129, 1520-1521.

18 (a) J. Lott and C. Weder, Macromol. Chem. Phys., 2010, 211, 28-34; (b) B. R. Crenshaw, M. Burnworth, D. Khariwala,
A. Hiltner, P. T. Mather, R. Simha and C. Weder, Macromolecules, 2007, 40, 2400-2408; (c) A. Pucci, F. Di Cuia, F. Signori and G. Ruggeri, J. Mater. Chem., 2007, 17, 783-790; (d) M. Kinami, B. R. Crenshaw and C. Weder, Chem. Mater., 2006, 18, 946-955; (e) B. R. Crenshaw and C. Weder, Macromolecules, 2006, 39, 9581-9589; (f) A. Pucci, M. Bertoldo and S. Bronco, Macromol. Rapid Commun., 2005, 26, 1043-1048; $(g)$ B. R. Crenshaw and C. Weder, Chem. Mater., 2003, 15, 4717-4724; (h) C. Löwe and C. Weder, Adv. Mater., 2002, 14, 1625-1629.

19 (a) M. Mitani, S. Ogata, S. Yamane, M. Yoshio, M. Hasegawa and T. Kato, J. Mater. Chem. C, 2016, 4, 2752-2760; (b) M. Mitani, S. Yamane, M. Yoshio, M. Funahashi and T. Kato, Mol. Cryst. Liq. Cryst., 2014, 594, 112-121; (c) S. Yamane, Y. Sagara, T. Mutai, K. Araki and T. Kato, J. Mater. Chem. C, 2013, 1, 2648-2656; (d) Y. Sagara and T. Kato, Angew. Chem., Int. Ed., 2011, 50, 9128-9132; (e) Y. Sagara, S. Yamane, T. Mutai, K. Araki and T. Kato, Adv. Funct. Mater., 2009, 19, 1869-1875; (f) V. N. Kozhevnikov, B. Donnio and D. W. Bruce, Angew. Chem., Int. Ed., 2008, 47, 6286-6289; $(g)$ Y. Sagara and T. Kato, Angew. Chem., Int. Ed., 2008, 47, 5175-5178.

20 (a) Y. Sagara, T. Komatsu, T. Ueno, K. Hanaoka, T. Kato and T. Nagano, J. Am. Chem. Soc., 2014, 136, 4273-4280; (b) Y. Sagara, T. Komatsu, T. Terai, T. Ueno, K. Hanaoka, T. Kato and T. Nagano, Chem.-Eur. J., 2014, 20, 1039710403; (c) Y. Sagara, T. Komatsu, T. Ueno, K. Hanaoka, T. Kato and T. Nagano, Adv. Funct. Mater., 2013, 23, 52775284.

21 T. Hirose and K. Matsuda, Chem. Commun., 2009, 58325834 .

22 (a) W. Wang, L. Wang, B. J. Palmer, G. J. Exarhos and A. D. Q. Li, J. Am. Chem. Soc., 2006, 128, 11150-11159; (b) J. Feng, Y. Zhang, C. Zhao, R. Li, W. Xu, X. Li and J. Jiang, Chem.-Eur. J., 2008, 14, 7000-7010; (c) F. Schlosser, M. Moos, C. Lambert and F. Würthner, Adv. Mater., 2013, 25, 410-414; (d) K. E. Brown, W. A. Salamant, L. E. Shoer, R. M. Young and M. R. Wasielewski, J. Phys. Chem. Lett., 2014, 5, 2588-2593.

23 M. Kasha, H. R. Rawls and M. A. El-Bayoumi, Pure Appl. Chem., 1965, 11, 371-392.

24 J. B. Birks, Rep. Prog. Phys., 1975, 38, 903-974.

25 (a) P. R. Ashton, D. Joachimi, N. Spencer, J. F. Stoddart, C. Tschierske, A. J. P. White, D. J. Williams and K. Zab, Angew. Chem., Int. Ed. Engl., 1994, 33, 1503-1506; (b) B. Neumann, D. Joachimi and C. Tschierske, Adv. Mater., 1997, 9, 241-244; (c) B. Neumann, T. Hegmann, C. Tschierske, B. Neumann and R. Wolf, Chem. Commun., 1998, 105-106; (d) B. Neumann, T. Hegmann, C. Wagner, P. R. Ashton, R. Wolf and C. Tschierske, J. Mater. Chem., 2003, 13, 778-784; (e) T. Hegmann, B. Neumann, R. Wolf and C. Tschierske, J. Mater. Chem., 2005, 15, 1025-1034. 